\title{
Analysis of Printed Circuit Boards strains using finite element analysis and digital image correlation
}

\author{
Alexandru Falk, Liviu Marsavina \\ University of Politehnica Timisoara, Romania \\ Alexandru.falk@yahoo.com, bttp://orcid.org/0000-0001-2345-6789 \\ liviu.marsavina@upt.ro),bttp://orcid.org/0000-0002-2345-6790 \\ Octavian Pop \\ University of Limoges, France \\ ion-octavian.pop@unilim.fr http://orcid.org/0000-0003-2345-6792
}

\begin{abstract}
This paper investigates the use of digital image correlation (DIC) and finite element analysis for strain measurement on Printed Board Circuits (PCBs).

Circuit boards (PCBs) are designed to mechanically support and electrically connect an electronic component assembly. Due to screw assemblies, the surface level differences on which the PCB is placed, the process of assembling the electronic components induces a certain state of stress and deformation in the PCB. The main components affected are microprocessors due to the way they are glued to PCBs with BGA - Ball grid arrays (BGA). Digital Image Correlation (DIC) is a full-field contactless optical method for measuring displacements and strain in experimental testing, based on the correlation of images taken during test. The experimental setup is realized with Dantec Q-400 system used for image capture and Istra 4D software for image correlations and data analyses. The maximum level of the obtained strain is compared with the allowable limit.

Finite element analysis (FEA) is a numerical method of analysis for stresses and strain in structures of any given geometry.
\end{abstract}

KEYWORDS. Digital image correlation; Finite element analysis; PCB; Strain.

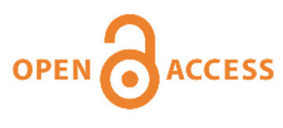

Citation: Falk, A., Marsavina, L., Pop, O., Analysis of Printed Circuit Boards strains using finite element analysis and digital image correlation, Frattura ed Integrità Strutturale, 51 (2020) 540-551.

Received: 30.10 .2019

Accepted: 08.12.2019

Published: 01.01.2020

Copyright: (C) 2020 This is an open access article under the terms of the CC-BY 4.0, which permits unrestricted use, distribution, and reproduction in any medium, provided the original author and source are credited.

\section{INTRODUCTION}

$\mathrm{P}$

rinted circuit boards (PCBs) are the boards that are used as the base in most electronics for physical support piece and wiring area for the surface-mounted and socketed electronical components. PCBs are most commonly made from fiberglass reinforced epoxy, or another composite material. 
In the current automotive industry, the allowable strain limit on PCBs is 700 microstrains. The reason for this is the size reduction of PCBs, change of solder material from Lead Solder $(\mathrm{SnPb})$ to lead-free solder and the use of increasingly complex electronic components.

The strains induced on PCB could be due to: differences of surface level on which the PCB is placed, assembly process of electronic components, bending of PCB due to assemblies, vibrations, temperature variation, and impact. These can cause problems in microprocessors BGAs (Ball grid array) and causes of failure for the electronic component. [1-7]

The current method used for strain measurement on PCBs is resistive strain gauge method presented in [8, 9]. With this method the strains can be determined only at the points where the strain gauges are placed. However, today, several optical techniques were developed for full filed strain measurement [10-12]. Among these methods, the Digital Image Correlation, the Mark Tracking technique or the grid methods seem to be better for characterizing the mechanical behavior in the case of PCBs.

The objective of this paper is to study the possibility of applying the Digital Image Correlation method (DIC) for full filed strain measurement and validation of a numerical model.

Finally, the numerical results obtained from finite element analysis (FEA) are compared with experimental results from digital image correlation (DIC) method.

\section{DigITAL IMAGE CORRELATION (DIC)}

$\mathrm{D}$ igital image correlation (DIC) offers unique opportunities for exploring full-field displacements and strain measurements of components subjected to various stresses (such as mechanical stresses or thermal stresses). This method is used for a variety of applications such as: large deformation measurements [13], crack analysis [14, 15], stress - strain diagram definition for new materials [16], damage and failure mechanism evaluation $[17,18]$, to measure of strain caused by temperature variations [19-25].

The basic principle of DIC operation is that after collecting the images during the application of the various loads, a comparison of the images is made following what happens with the points of random pattern divided into several subgroups compared to the image in which the surface is undeformed, Fig. 1, [26-29]. The displacements measured by DIC represent the displacement vectors corresponding to displacements of all subsets centers. According to DIC principle, the displacements are estimated by searching the subsets changes (translation + rotation + rigid body motion) between the undeformed and the deformed images.

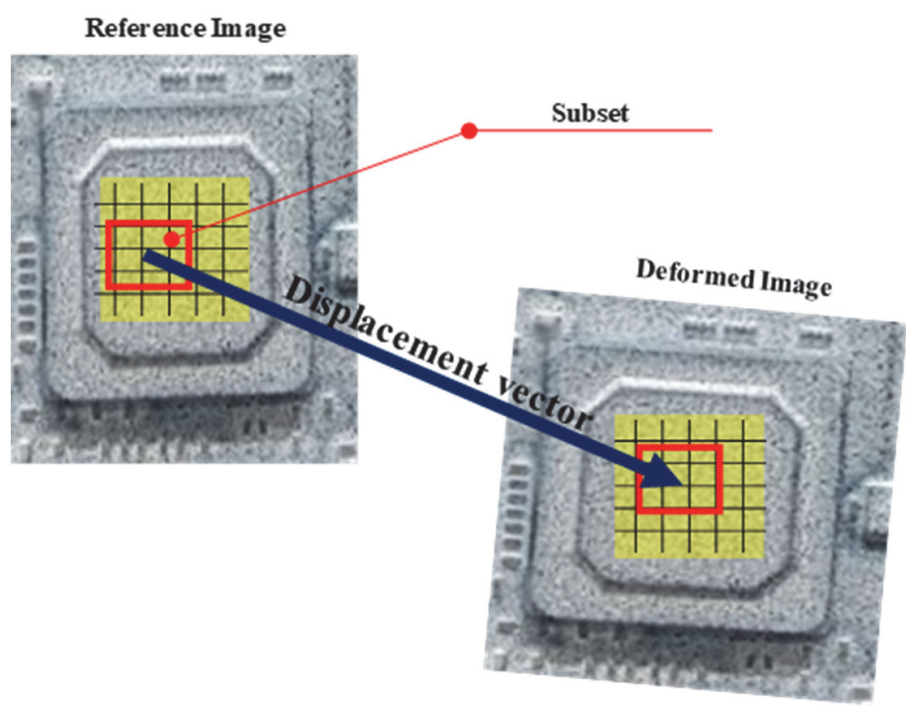

Figure 1: DIC basic principle

To implement DIC method three steps are required: sample preparation by applying a random speckle pattern, then recording the images before and during the load, and in the last phase processing of recorded images. Image processing can be done with several correlation algorithms developed over time. 


\section{EXPERIMENTAL SET-UP}

7 he experimental PCB sample is illustrated in Fig. 2. A double-sided PCB is made from top to bottom from Soldermask, Copper and Substrate - glass fibers reinforcement epoxy (FR4). The FR4 material gives to the board rigidity. Multi-layer PCBs consist of a series of three or more double-layered PCBs. These boards are then secured together with a specialized glue and sandwiched between pieces of insulation to ensure that excess heat doesn't melt any of the components. The illustration shows that the PCB is assembled between Housing and Cover using four screws M2.5.

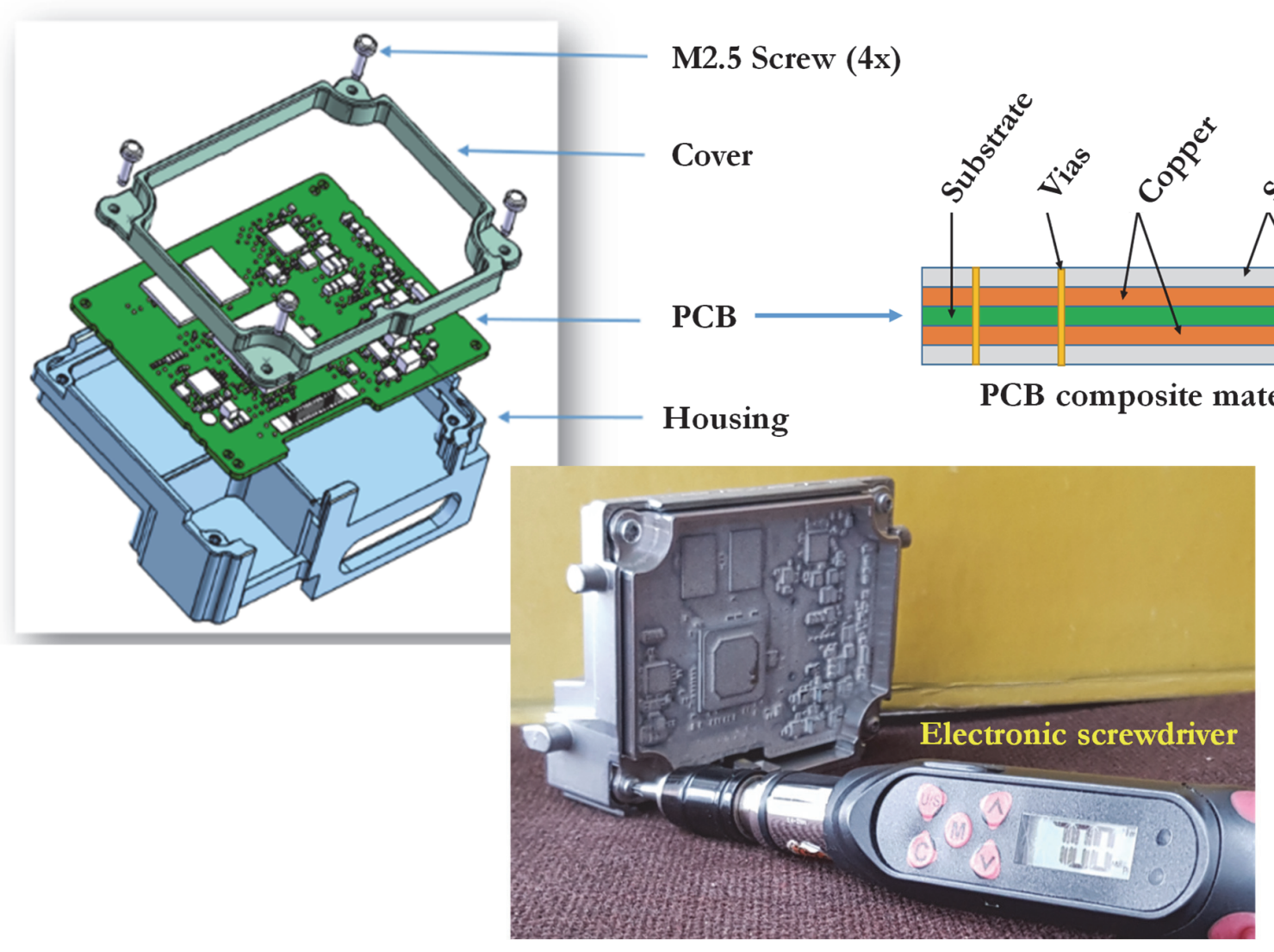

Figure 2: PCB composite material and experimental sample

With regard to the assembly conditions, the PCB is bended due to difference in height of bumps, which are $0.2 \mathrm{~mm}$ above the PCB seating surface. All these geometrical features influence the mechanical behavior of PCBs. It should be added that the height of bumps play an important part in the mechanical behavior of PCB. In order to see the influence of bumps on the strain distribution for this study were considered two types of loading: Loading case 1 with two bumps on the cover and Loading case 2 without bumps on the cover as showed in Fig 3. Screwing sequence for the four screws was Screw 1, 2, 3 and 4 and the torque was $0.7 \mathrm{Nm}$ applied with an electronic screwdriver (see Fig. 2). Concerning the measurement devices, in the present study the sample deformation was recorded using Digital Image Correlation. The experimental set-up including the sample and the measurement devices are illustrated in Fig. 4.

The equipment used to capture and process the images for DIC analysis was the Dantec Q-400 system. As illustrated in Fig. 4, the optical system consists of two CCD cameras coupled with LED light source. Each camera is equipped with lenses optimized for metrology applications. The illumination system is equipped with 12 high power LED's. The using of LED light source allows us to obtain a most homogenous intensity distribution in the ROI without the heating of sample that ensures excellent measurement conditions. 


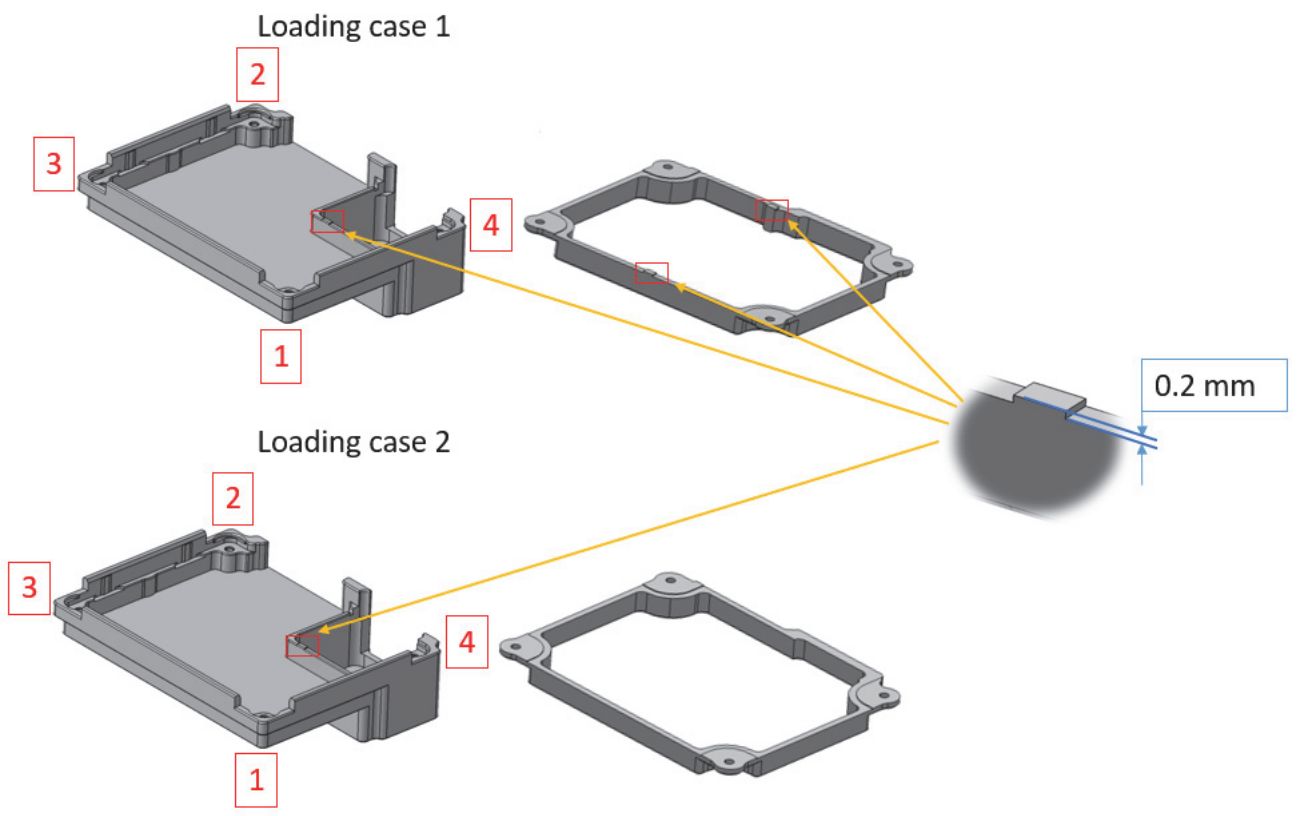

Figure 3: Bumps arrangement (Loading case 1: cover with two bumps and Loading case 2: cover without bumps).

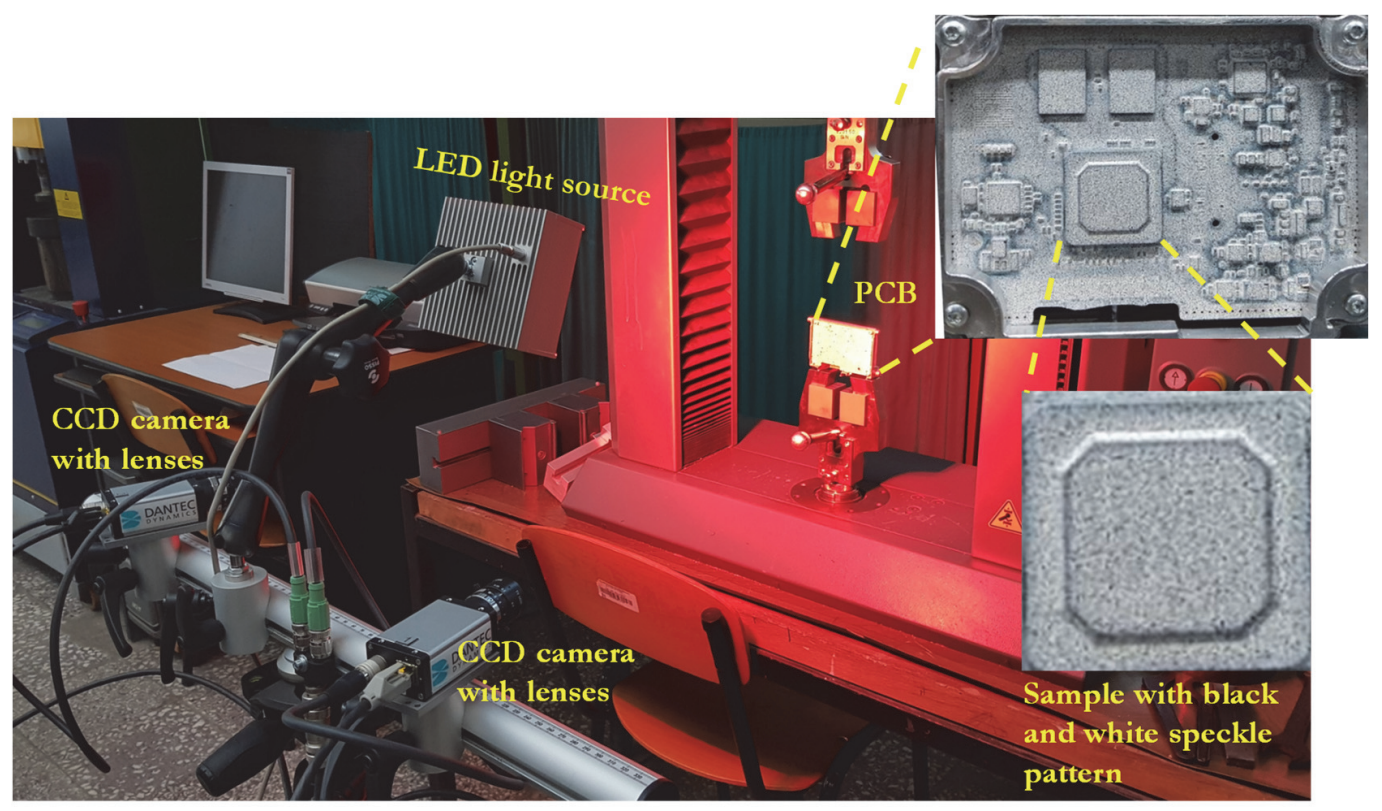

Figure 4: Experimental setup and PCB with black and white speckle pattern.

\section{Finite ElEMENT ANALYSIS}

$\mathrm{F}$

inite Element Analysis (FEA) is usually used to determine the strain fields on electronic components, taking into account the complex electrical, thermal and mechanical phenomena [30-33]. This method can also be used in case of PCBs, for determination of strain distribution across the PCB, due to electrical, thermal and mechanical loadings. It is important to know the strain distribution across PCB surface to avoid positioning of sensitive components (such as microprocessors bounded to PCBs via BGAs or small electronic components) in critical areas. 
The Ansys Workbench 18.1 commercial software was used for the finite element analysis. To simplify the model, electronic components were considered simple geometry blocks with a generic material (a hard plastic) attributed and the PCB was considered linear orthotropic (FR4 material), with properties in first instance determined experimentally by authors (unpublished work) and in second simulation a FR4 material model from Ansys material database. Tab. 1 gives the thermomechanical properties of FR4 material. These were implemented in the finite element model. The analysis of these properties shows very well the material anisotropy. It should be added that the PCB components rigidity accentuate the effects of anisotropy. This aspect can cause a different deformation distribution of PCB components.

\begin{tabular}{|c|c|c|c|}
\hline \multirow[t]{2}{*}{ Property } & \multirow[t]{2}{*}{ Unit } & $\begin{array}{l}\text { FR4 experimental } \\
\text { determined }\end{array}$ & $\begin{array}{l}\text { FR4 Ansys } \\
\text { database }\end{array}$ \\
\hline & & Value & Value \\
\hline \multicolumn{4}{|l|}{$\begin{array}{c}\text { Orthotropic Instantaneous Coefficient of Thermal } \\
\text { Expansion }\end{array}$} \\
\hline Coefficient of Thermal Expansion X direction & $\mathrm{C}^{-1}$ & $1.35 \mathrm{E}-05$ & $1.25 \mathrm{E}-05$ \\
\hline Coefficient of Thermal Expansion Y direction & $C^{-1}$ & $1.35 \mathrm{E}-05$ & $1.40 \mathrm{E}-05$ \\
\hline Coefficient of Thermal Expansion Z direction & $C^{-1}$ & 4.50E-05 & $8.20 \mathrm{E}-05$ \\
\hline \multicolumn{4}{|l|}{ Orthotropic Elasticity } \\
\hline Young's Modulus X direction & $\mathrm{MPa}$ & $1.69 \mathrm{E}+04$ & $2.04 \mathrm{E}+04$ \\
\hline Young's Modulus Y direction & $\mathrm{MPa}$ & $1.69 \mathrm{E}+04$ & $1.84 \mathrm{E}+04$ \\
\hline Young's Modulus Z direction & $\mathrm{MPa}$ & $7.40 \mathrm{E}+03$ & $1.50 \mathrm{E}+04$ \\
\hline Poisson's Ratio XY & - & 1.10E-01 & $1.10 \mathrm{E}-01$ \\
\hline Poisson's Ratio YZ & - & 3.90E-01 & $9.00 \mathrm{E}-02$ \\
\hline Poisson's Ratio XZ & - & $3.90 \mathrm{E}-01$ & $1.40 \mathrm{E}-01$ \\
\hline Shear Modulus XY & $\mathrm{MPa}$ & $7.60 \mathrm{E}+03$ & $9.20 \mathrm{E}+03$ \\
\hline Shear Modulus YZ & $\mathrm{MPa}$ & $3.30 \mathrm{E}+03$ & $8.40 \mathrm{E}+03$ \\
\hline Shear Modulus XZ & $\mathrm{MPa}$ & $3.30 \mathrm{E}+03$ & $6.60 \mathrm{E}+03$ \\
\hline
\end{tabular}

Table 1: Thermomechanical properties of FR4 material.

Boundary conditions were applied as bolt pretension of $1800 \mathrm{~N}$ equivalent of $0.7 \mathrm{Nm}$, according to screw supplier. After the mesh a total number of 80254 tetrahedral elements, connected in 266649 nodes were obtained, Fig. 5. The two loading scenarios (loading case 1 and 2), presented in Fig. 3 were adopted for the simulation, and for each loading case the two sets of material properties for FR4 presented in Tab. 1 were defined.

By solving the finite element analysis, the maximum principal strain distribution over PCB was obtained, this is shown in Fig. 6. It can be observed that the maximum principal strains are localized near to the big component (microprocessor) and near the fixing holes, the strain limit is over the admissible value (700 microstrains).

For a good understanding of maximum principal strain distribution in the area of microprocessor the results were interrogated, according to the paths shown in Fig. 7 (A1-A2, B1-B2, C1-C2, D1-D2) and the resulted values of maximum principal strain are presented in Fig. 8. 


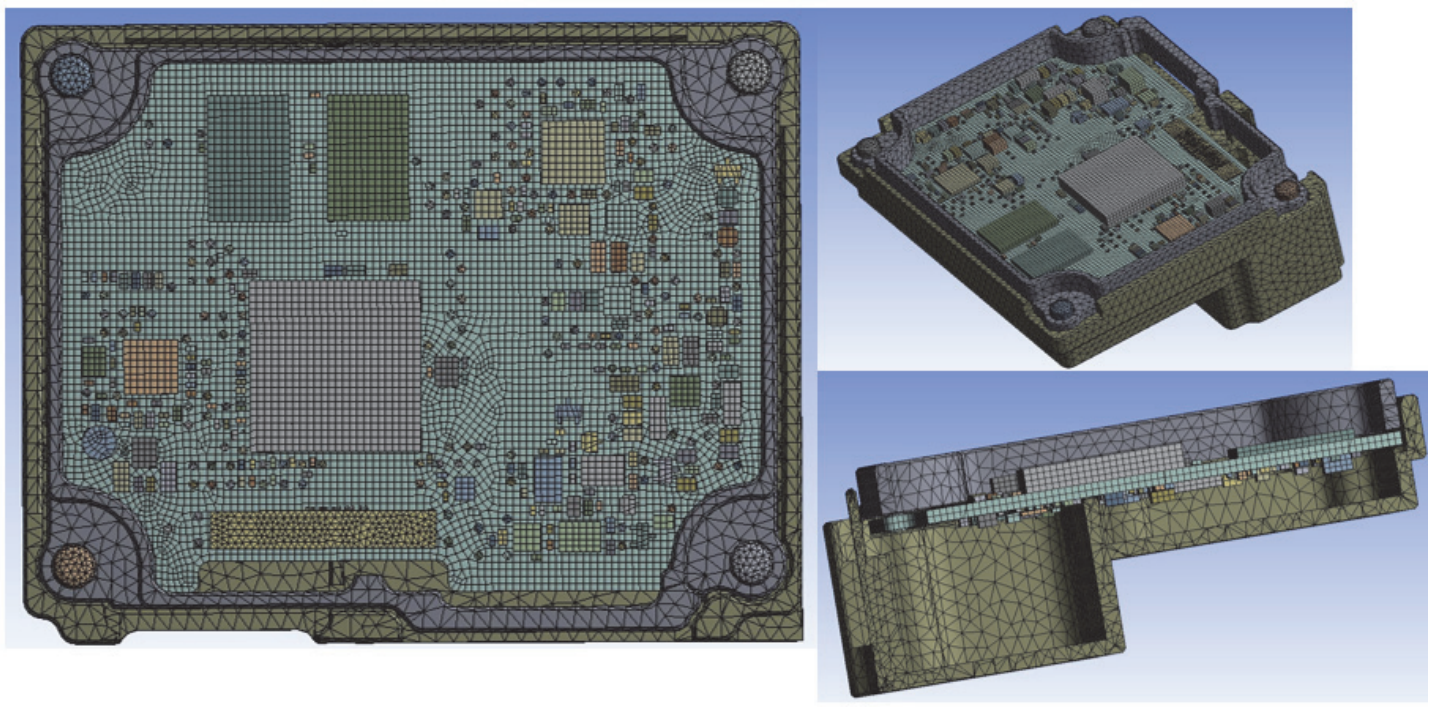

Figure 5: Finite Element Mesh.

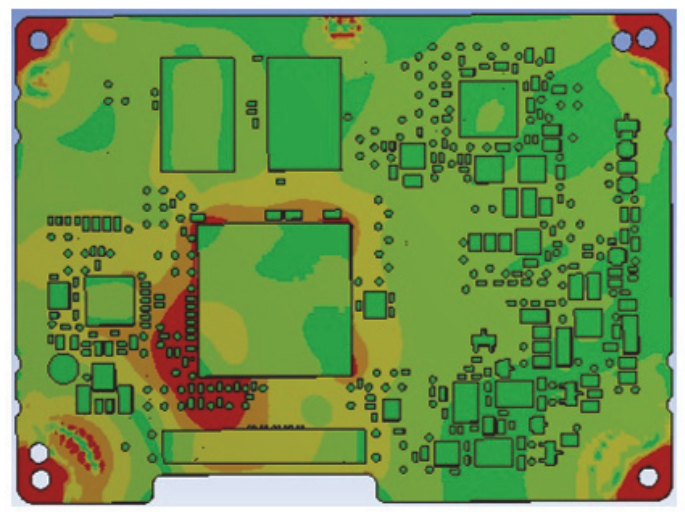

a)

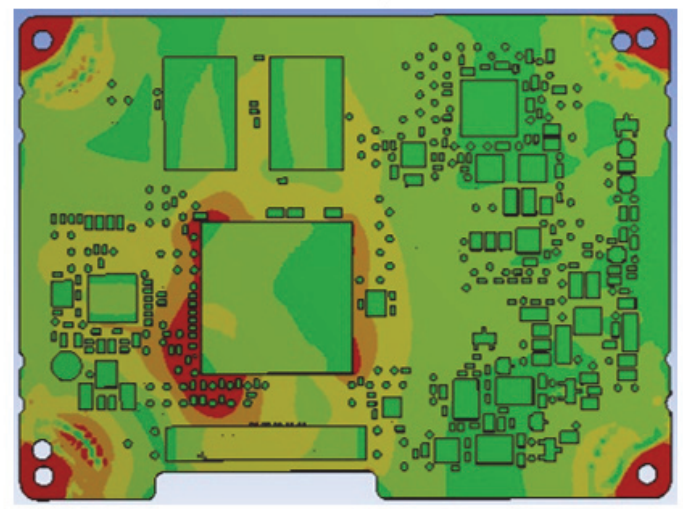

c)

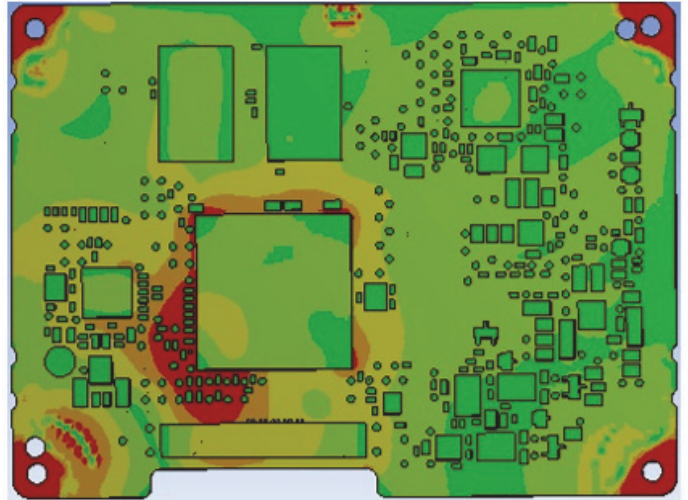

b)

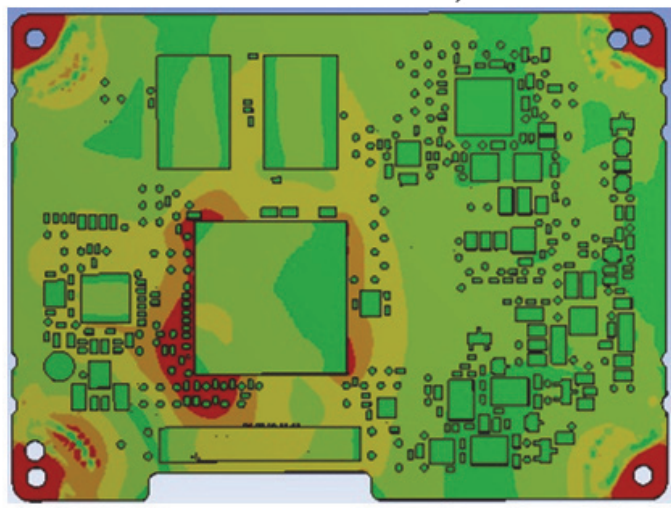

d)

Figure 6: FEA results for maximum principal strains: a) Loading case 1 - FR4 experimental determined; b) Loading case 1 - FR4 Ansys database; c) Loading case 2- FR4 experimental determined; d) Loading case 2 - FR4 Ansys database.

The influence of material properties of FR4 (experimental and from ANSYS database) has low effect on the results. It could be observed higher values of maximum principal strains on the path A1-A2 for the Loading case 2, respectively Lode case 1 for D1-D2 path. On this path, the maximum principal strains exceeded the 700 microstrain limit for Loading case 1 through the path, and on part of the path (between 0 to $7 \mathrm{~mm}$ ) for Loading case 2. 


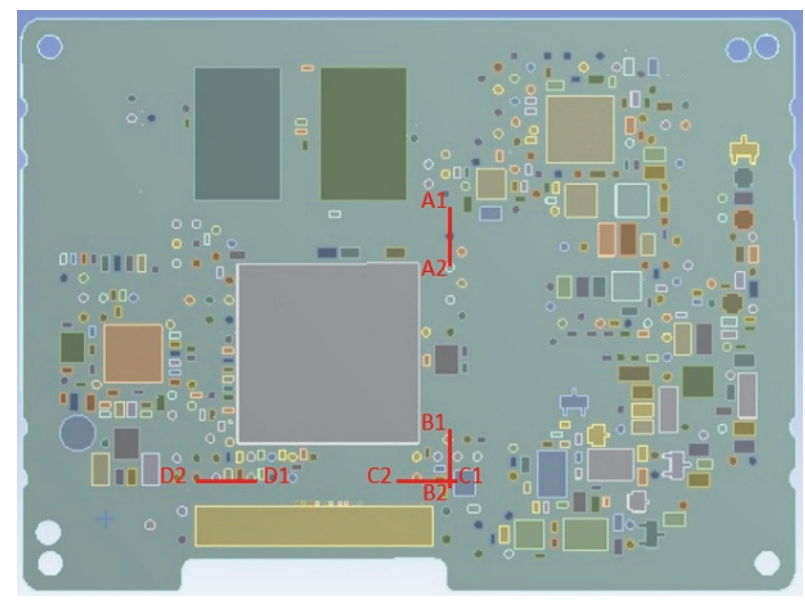

Figure 7: Definition of paths to interrogate the maximum principal strains results

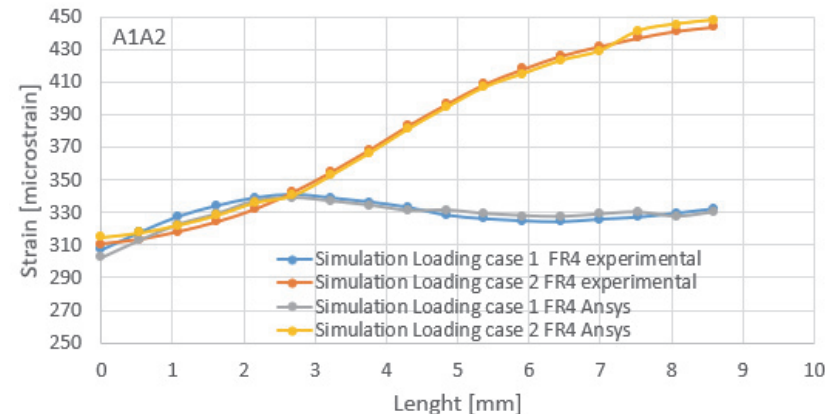

a)

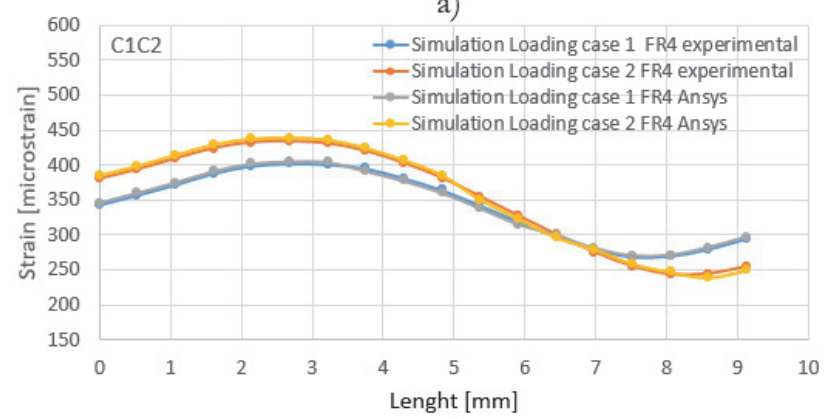

c)

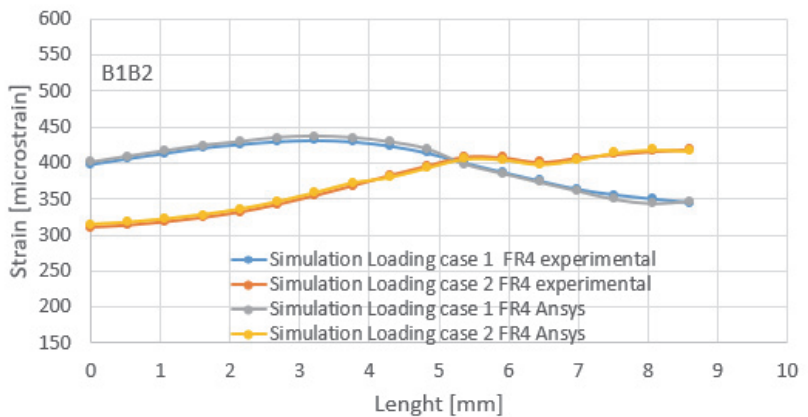

b)

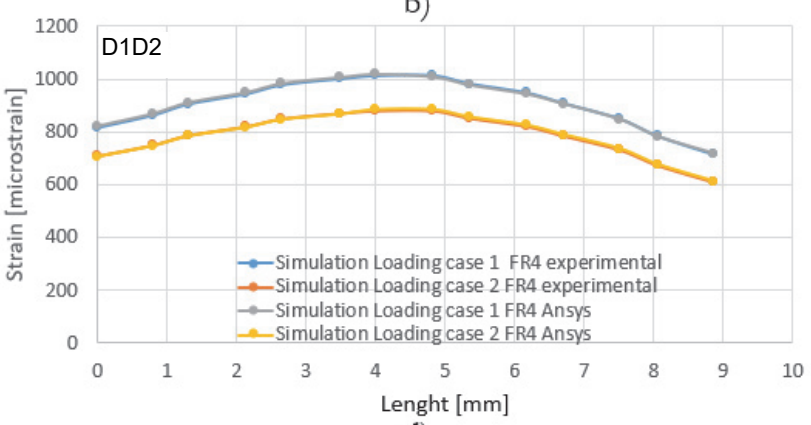

d)

Figure 8: Maximum principal strain distribution on PCB (FEA results): a) A1-A2; b) B1-B2; c) C1-C2; d) D1-D2.

\section{DISCUSSIONS AND CONCLUSION}

A s illustrated above, in Fig. 4, in order to properly acquire and process images for DIC applications a random speckle pattern has to be firstly applied on the PCB surface, according with principle of DIC. This is commonly done by applying a sprayed black ink over a smooth white layer (Fig. 4).

Before testing the DIC system was calibrated according with ISTRA 4D guide. Fig. 9 shows also a picture of the calibration process with a specific target. This step allows us to set the camera parameters (gain and expose time, open aperture, focus) function to the ROI size (ROI - Region Of Interest). The angle between the cameras was between 40-60․ 


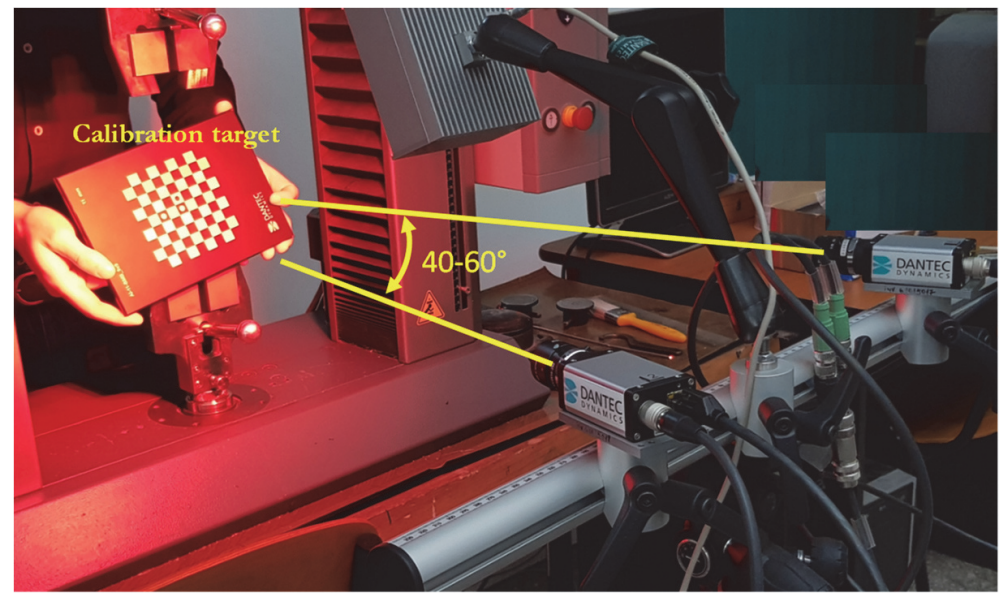

Figure 9: Correlation system with calibration target.

After capturing the images, the correlation and analysis was performed with Istra 4D software. The strain analysis was performed into ROI defined on the PCB surface. As can be seen in Fig. 10, the ROI includes the PCB components.

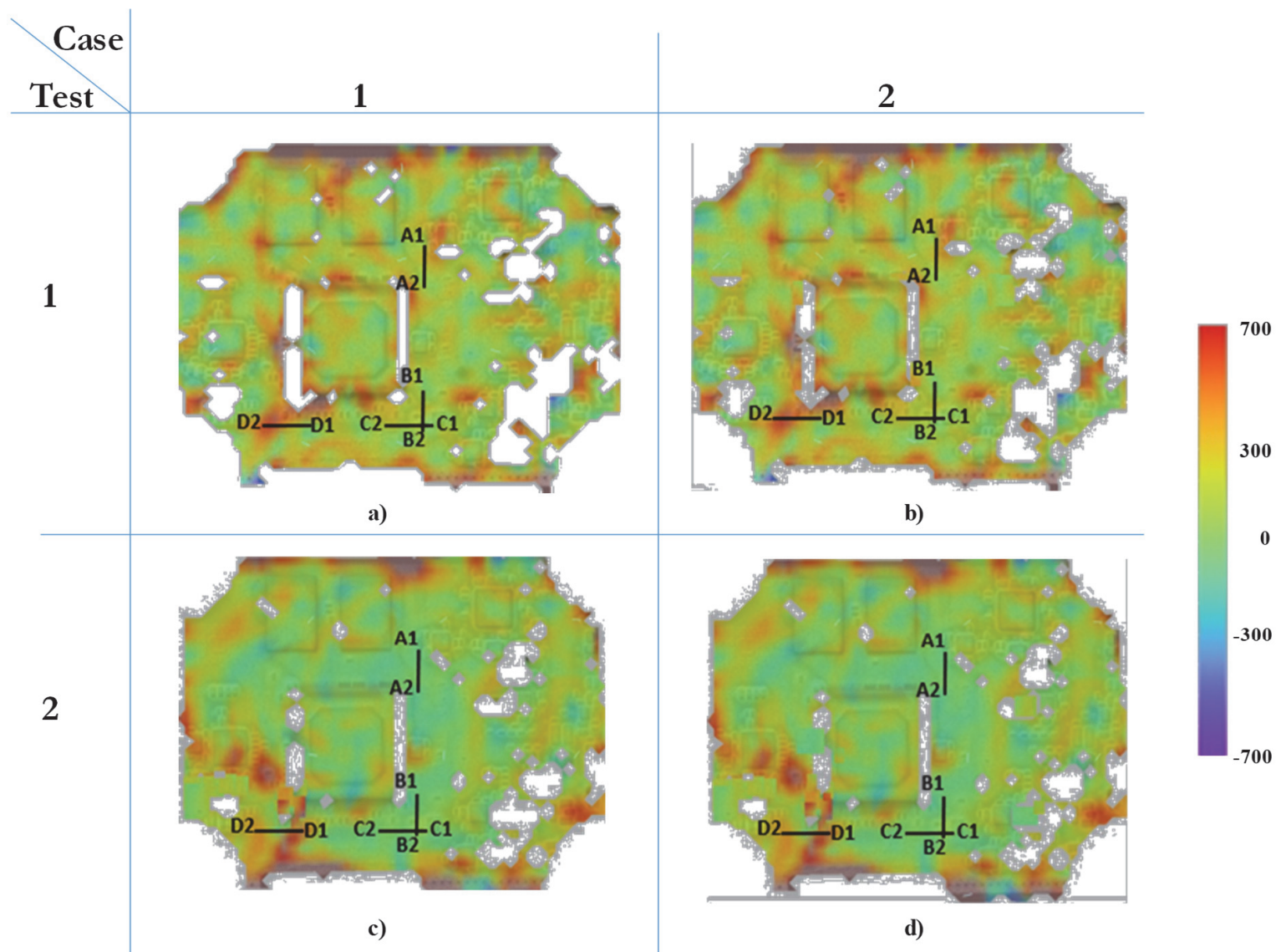

Figure 10: DIC maximum principal strains distribution on PCB: a) Loading case 1 Test 1; b) Loading case 1 Test 2; c) Loading case 2 Test 1; d) Loading case 2 Test 2.

According with principle of DIC this region was subdivided by the small subsets. The displacement and strain fields were calculated into these subsets using a correlation algorithm. The maximum principal strain distribution was illustrated in Fig. 10. These results reveal the global behavior of the PCB. Moreover, thanks to DIC, a more closed analysis can be performed for each PCB component. This analysis reveals that in the case of the "Loading case 1" the PCB components are most 
strained that in the case of "Loading case 2". These facts show clearly the influence of housing and cover geometries on the strain distribution. These distributions must be also correlated with the bumps arrangement shown in Fig. 3. These aspects can have a strong influence on the damage and the failure of the PCB components. The analysis of the strain distribution near the connection between the PCB and the components shows that these connections are subject to the important strains. This must be avoided, in order to prevent the components disbonding.

The different segments indicated in Fig. 10 were used as the optical gauges to calculate the local maximum principal strain. The gauge positions are the same as the segments draw to interrogate the finite element analysis results. The idea is to compare the finite element analysis with the experimental measures by DIC using the same paths. A comparison between the experimental values obtained as a mean from the two tests ("test 1" and "test 2") and the numerical results (obtained for the properties of FR4 from Ansys database) are plotted in Fig. 11. According to Fig. 8 and Fig. 11 could be observed that the DIC maximum principal strain results are in the same range with the results from the finite element analysis. This comparison shows a very good agreement between experimental and numerical results of maximum principal strain. The observed errors may be related to differences between boundary conditions implemented in the finite element analysis and real loading conditions from experiments.
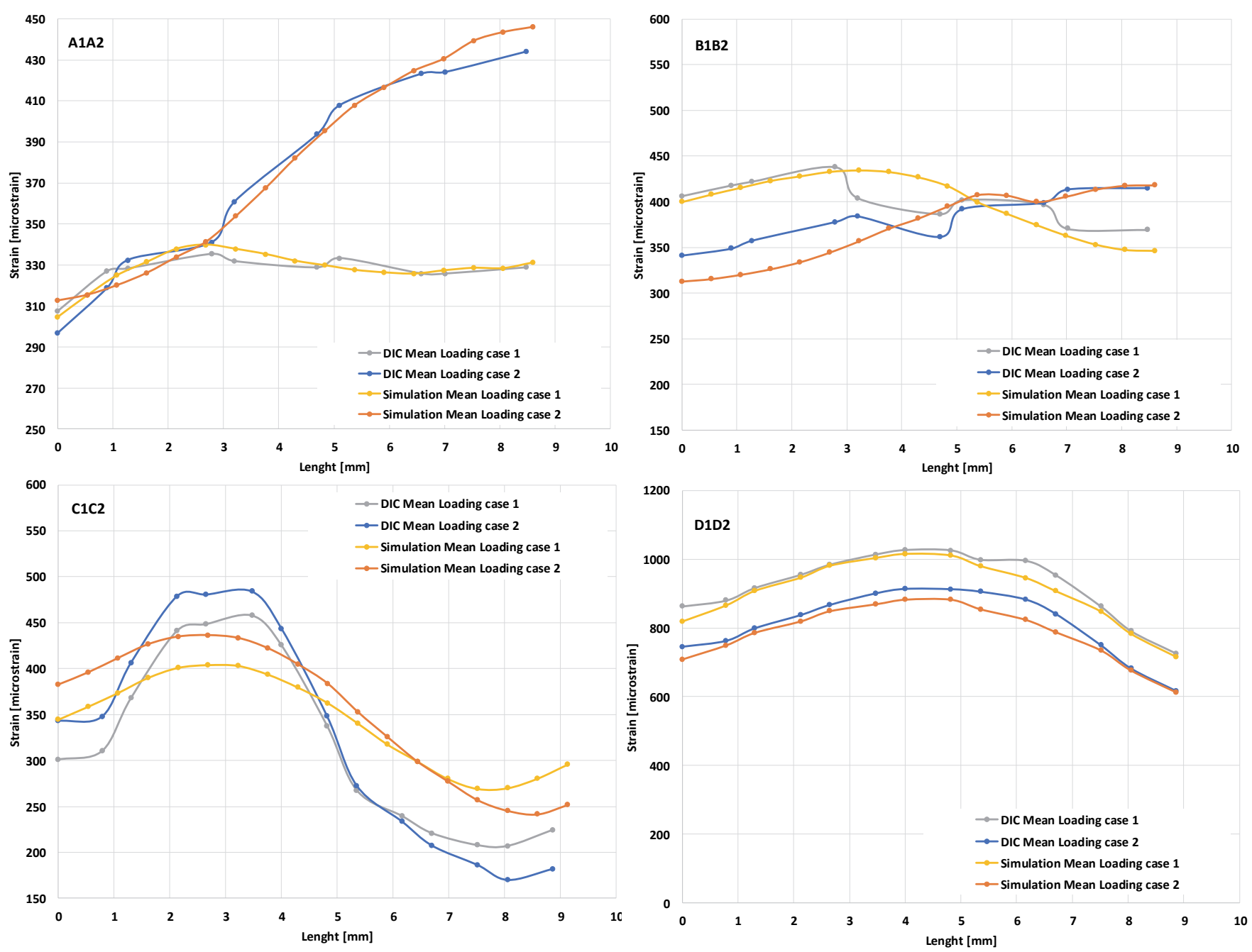

Figure 11: Maximum principal strain comparison between DIC (mean values for the 2 tests) and FEA results

The allowable strain limit of 700 microstrains is exceeded for both evaluation approaches on the path D1-D2.

To conclude, the procedure based on DIC measurements allow an accurate measurement of strains on PCB's, having the advantage of full field and minimum surface preparation.

However, the numerical simulation results are easy to be obtained, but the results should be experimentally validated. In current practice, the experimental validation is carried on based on strain gauge measurement [8, 9, 34]. The methodology 
proposed here and based on DIC is more reliable (because the measurements are not influenced by the electro-magnetic field) and efficient to monitor the full field distribution of strains on the PCB's, with a minimum preparation of PCB surface.

\section{ACKNOWLEDGEMENTS}

7 his work was supported by a grant of the Romanian Ministry of Research and Innovation, project number 10PFE/16.10.2018, PERFORM-TECH-UPT - The increasing of the institutional performance of the Politechnica

University of Timișoara by strengthening the research, development and technological transfer capacity in the field of "Energy, Environment and Climate Change", within Program 1 - Development of the national system of Research and Development, Subprogram 1.2 - Institutional Performance - Institutional Development Projects - Excellence Funding Projects in RDI, PNCDI III.

\section{REFERENCES}

[1] Gu, J., Lei, Y., Lin, J., Fu, H., Wu, Z. (2017). The Failure Models of Lead-Free Sn-3.0Ag-0.5Cu Solder Joint Reliability Under Low-G and High-G Drop Impact, Journal of Electronic Materials, 46 (2), pp. 1396-1404.

[2] Benabou, L., Sun, Z., Dahoo, PP. R. (2013). A thermo-mechanical cohesive zone model for solder joint lifetime prediction, International Journal of Fatigue, 49, pp. 18-30.

[3] Kok, C. K., Ng, W. J., Ooi, C. C., Liew, K. W. (2016). Ball-grid-array solder joint model for assembly-level impact, Microelectronic Reliability, 65, pp. 184-191.

[4] Sinkovics, B., Krammer, O. (2009) Board level investigation of BGA solder joint deformation strength, Microelectronic Reliability, 49 (6), pp. 573-578.

[5] Wong, T. E., Palmieri, F. W., Reed, B. A., Fenger, H. S., Cohen, H. M., Teshiba, K. T. (2000). Durability/reliability of BGA solder joints under vibration environment, Electronic Components and Technology Conference, pp. 1083-1088.

[6] Han, J., Guo, F., Liu, J.PP. (2017). Early stages of localized recrystallization in Pb-free BGA solder joints subjected to thermomechanical stress, Journal of Alloys and Compounds, 704, pp. 574-584.

[7] Amalu, E.H., Ekere, N.N. (2012). High temperature reliability of lead-free solder joints in a flip chip assembly, Journal of Materials Processing Technology, 212, pp. 471-483.

[8] IPC, IPC JEDEC 9704A: Printed Wiring Board Strain Gage Test Guidline (2012).

[9] IPC, Guidance for Strain Gage Limits for Printed Circuit Assemblies. (2011).

[10] Moulart, R., Pierron, F., Hallett, S.R., Wisnom, M.R. (2010). Full-field strain measurement and identification of composites moduli at high strain rate with the virtual fields method, Experimental Mechanics, 51, pp. 509-536.

[11] Luo, PP. F., Chao, Y.J., Sutton, M.A., Peters, W.H. Accurate measurement of three-dimensional deformations in deformable and rigid bodies using computer vision, Experimental Mechanics, 33, pp. 123-132.

[12] Chean, V., Robin, E., Abdi, R., Sangleboeuf, J.C., Houizot, PP. (2011). Use of the mark-tracking method for optical fiber characterization, Optics \& Laser Technology, 43, pp. 1172-1178.

[13] Tarigopula, V., Hopperstad, O.S., Langseth, M., Clausen, A.H., Hild, F., Lademo, O.-G., Eriksson, M. (2008). A Study of Large Plastic Deformations in Dual Phase Steel Using Digital Image Correlation and FE Analysis, Experimental Mechanics, 48, pp. 181-196.

[14] Tung, S.H., Shih, M.H., Sung, W.PP. (2008). Development of digital image correlation method to analyses crack variations of masonry wall, Sadhana, 33 (6), pp. 767-779.

[15] Marsavina, L., Sadowski, T., Knec, M. (2013) Crack propagation paths in four point bend Aluminium-PMMA specimens, Engineering Fracture Mechanics, 108, pp. 139-151.

[16] Mol'kov, Yu, V. (2013). Application of the method of digital image correlation to the construction of stress-strain diagram, Materials Science, 48 (6), pp. 832-837.

[17] Voiconi, T., Linul E., Marsavina, L., Sadowski T., Knec M. (2014) Determination of flexural properties of rigid PUR foams using digital image correlation, Solid State Phenomena, 216, pp. 116-121.

[18] Apostol, D.A., Constantinescu D.M., Marsavina, L., Linul, E. (2014) Analysis of Deformation Bands in Polyurethane Foams, Key Engineering Materials, 601, pp. 250-253.

[19] Wang, B., Pan, B. (2016). Subset-based local vs. finite element-based global digital image correlation: A comparison study, Theoretical \& Applied Mechanics Letters 6, pp. 200-208. 
[20] La Rosa, G., Clienti, C. and Garrano, A. M. C. (2015). The use of digital image correlation to correct the thermoelastic curves in static tests, Procedia Structiral Integrity, 2, pp. 2140-2147.

[21] Ramosa, T., Furtado, A., Eslami, S., Alves, S., Rodrigues, H., Arêde, A., Tavares, PP. J., Moreira, PP. M. G. PP. (2015). $2 \mathrm{D}$ and 3D Digital Image Correlation in Civil Engineering - Measurements in a Masonry Wall, Procedia Engineering, 114, pp. 215-222.

[22] Pan, B., Yuan, J., Xi, Y. (2014). Strain field denoising for digital image correlation using a regularized cost-function, Optics and Lasers in Engineering, 65, pp. 9-17.

[23] Tekieli, M., De Santis, S., Felice, G., Kwiecien, A., Roscini, F. (2017). Application of Digital Image Correlation to composite reinforcements testing, Composite Structures, 160, pp. 670-688.

[24] Hild, F., Roux, S. (2006). Digital Image Correlation: from Displacement Measurement to Identification of Elastic Properties - a Review, Journal compilation, 42, pp. 69-80.

[25] Malesa, M., Malowany, K., Tomczak, Ur., Siwek, B., Małgorzata, K., Lewandowska, A.S. (2013). Application of 3D digital image correlation in maintenance and process control in industry, Computers in Industry, 64, pp. 1301-1315.

[26] Li, J., Xiea, X., Yang, G., Zhang, B., Siebert, T., Yang, L. (2017). Whole-field thickness strain measurement using multiple camera digital image correlation system, Optics and Lasers in Engineering, 90, pp. 19-25.

[27] Pan, B., Qian, K., Xie, H., Asundi, A. (2009). Two-dimensional digital image correlation for in-plane displacement and strain measurement: a review, Meas. Sci. Technol. 20 (6), 062001.

[28] Hung, PP. C., Voloshin, A.S. (2003). In-plane strain measurement by digital image correlation, Journal of the Brazilian Society of Mechanical Sciences and Engineering, XXV, 3.

[29] Lin, S., Lienert, U., Haas, S., Gutschimidt, S. (2015). Strain Measurement by Digital Image Correlation.

[30] Chiozzi, D., Bernardoni, M., Delmonte, N., Cova, PP. (2016). A simple 1-D finite elements approach to model the effect of PCB in electronic assembly, Microelectronic Reliability, 56, pp. 126-132.

[31] Fan, X., Pei, M., Bhatti, PP. K. (2006). Effect of finite element modeling techniques on solder joint fatigue life prediction of flip-chip BGA packages, Electronic Components and Technology Conference.

[32] Li, L., Kimb, S.M., Song, S.H., Ku, T.W., Song, W.J., Kim, J., Chong, M.K., Park, J.W., Kang, B.S. (2008). Finite element modeling and simulation for bending analysis of multi-layer printed circuit boards using woven fiber composite, Journal of Materials Processing Technology, 201, pp. 746-750.

[33] Zahn, B. A. (2002). Finite element-based solder joint fatigue life predictions for a same die size-stacked-chip scale-ball grid array package, Technology Symposium: International Electronics Manufacturing Technology (EMT) Symposium.

[34] Falk, A., Marsavina, L., Pop, O. (2019). Experimental determination of strain distribution on Printed Circuit Boards using Digital image correlation, Procedia Structural Integrity, 18, (2019) 214-222. 